National Conference of Creative Industry:

Sustainable Tourism Industry for Economic Development

Universitas Bunda Mulia, Jakarta, 5-6 September 2018

e-ISSN No: 2622 - 7436

\title{
HUBUNGAN MOTIVASI KERJA DALAM MENINGKATKAN KINERJA ROOM ATTENDANT DI HOSEKEEPING NOVOTEL NUSA DUA BALI
}

\author{
Asmawi \\ Sahid Institute of Tourism Jakarta, derinta.derinta@ gmail.com
}

\begin{abstract}
This study aims to : ( 1 ) determine how the motivation and performance of the Department Housekeeping room attendant at the Novotel Nusa Dua Bali ( 2 ) determine the relationship between motivation and performance room attendant and how much the relationship. This research was conducted at the Novotel Nusa Dua Bali hotel and resident. This type of research is descriptive quantitative by using primary data originating from field research and secondary data through library research. Data was collected through observation, interviews, questionnaires and literature. The information consists of Floor supervisors and Room Attendant at the Novotel Nusa Dua Bali. The data analysis technique used is descriptive quantitative methods of data analysis product moment correlation pearson to calculate the relationship between two variables, motivation and performance of the second variable interval scale. While the indicator of the performance is loyalty, work, teamwork, ability, initiative and responsibility. From the research results between motivation and performance have a correlation coefficient of 0.71 coefficient interval 0.71 to 0.90 which has a high level of relationship or a strong and reliable. The calculation result of hypothesis test obtained $t$ counted $=4.157>t$ table $=2,110$ then accepted Ha Ho is rejected. This means that between motivation and performance room attendant significant correlation. Results of this study are expected to be useful for all parties, especially the management to further improve and maintain the motivation to work so that the employee's performance can be maintained and continues to increase along with the progress and objectives of the company
\end{abstract}

Keywords : work motivation, performance, room attendant

\section{PENDAHULUAN}

Bali sebagai tujuan pariwisata yang mempunyai keunikan alam dan berbagai hasil senibudayanya. Untuk menunjang keberhasilan pariwisata di Bali, diperlukan sarana akomodasi. Dalam UU.No 10 Tahun 2009 tentang kepariwisataan mengatakan " usaha penyediaan akomodasi adalah usaha yang menyediakan pelayanan penginapan dan dapat dilengkapi dengan pelayanan pariwisata lainnya". Usaha penyediaan akomodasi dapat berupa hotel, vila, pondok wisata, bumi perkemahan, persinggahan, aravan, dan akomodasi lainnya yang digunakan untuk tujuan pariwisata.

Novotel merupakan akomodasi yang berupa hotel residen yang berada dikawasan BTDC (Bali Tourism Development Corporate) kompleks, Nusa Dua Bali.Novotel Nusa Dua dikategorikan sebagai hotel residen karena tidak hanya menyediakan jenis kamar hotel, tapi juga apartemen untuk disewakan dalam jangka waktu lama.Untuk mendukung kegiatan operasional, maka dibagi dalam beberapa departemen penting dengan tugas dan fungsi masing-masing. Bagian penting yang juga mendukung kegiatan dalam hotel ialah Housekeeping department. 


\section{National Conference of Creative Industry: Sustainable Tourism Industry for Economic Development}

Universitas Bunda Mulia, Jakarta, 5-6 September 2018 e-ISSN No: 2622 - 7436

Housekeeping department ialah bagian yang bertugas dan bertanggung jawab untuk menjaga kebersihan, kerapihan, keindahan dan kenyamanan di seluruh hotel khususnya kamar tamu.Subbagian housekeeping yang memiliki peran penting ialah room section, karena bertugas menjaga kebersihan, kerapihan, kenyamanan dan kelengkapan kamar-kamar tamu dengan petugas yang disebut Room Boy/maid atau room attendent.

Dalam bekerja selain pengetahuan dan keterampilan, dibutuhkan semangat kerja yang tinggi serta motivasi kerja.Karena walaupun karyawan sudah memiliki keterampilan dan pengetahuan dalam bidangnya, masih saja ada karyawan yang melupakan tugasnya.Seperti dengan belum melaksanakan standar operasional secara penuh, belum menggunakan waktu kerja dengan maksimal, serta ada masih ada beberapa room attendant yang acuh tak acuh dalam menjalankan tugas, juga penggunaan peralatan yang belum sesuai.Selain itu juga masih saja ada keluhan tamu yang ditujukan untuk bagian kamar.

Motivasi adalah hal yang menyebabkan, menyalurkan dan mendukung perilaku manusia, supaya mau bekerja giat dan antusias mencapai hasil yang optimal (Prabu, 2005).Perlu ada pemberian motivasi berupa finansial maupun nonfinansial seperti, penghargaan, kenaikan jabatan serta pelatihan.Namun jika dilihat dari kinerja room attendant, masih kurangnya motivasi kerja yang diberikan dan perlu untuk ditingkatkan.Contohnya seperti pelatihan yang monoton, dan juga pengawasan yang kurang makasimal dari supervisor.

Ketika pihak menajemen sudah mengetahui hambatan yaitu kurangnya motivasi kerja bagi para karyawan, maka akan mudah mengambil tindakan selanjutnya untuk meningkatkan kinerja karyawan. Dan dari motivasi yang diberikan diharapkan para room attendant dapat memiliki semangat kerja yang baru, semakin merasa nyaman dengan lingkungan kerja dan percaya diri sehingga dapat memberikan kinerja terbaik. Motivasi menjadi perilaku, andaikata perilaku tersebut efektif, maka akibatnya berupa kinerja atau hasil kerja yang tinggi

Adapun tujuan dari penelitian diantaranya :

Mengetahui motivasi kerja room attendant di housekeeping department Novotel Nusa Dua Bali.

Mengetahui kinerja room attendant di housekeeping department Novotel Nusa Dua Bali

Mengetahui hubungan antara motivasi kerja dan kinerja room attendant serta mengetahui seberapa besar hubungan tersebut.

\section{METODE PENELITIAN}

Di dalam buku Metodelogi Penelitian Pariwisata dan Perhotelan, I Gusti Bagus Rai Utama dan Ni Made Eka Mahadewi (2012:131)

“ jika serangkaian observasi atau pengukuran dapat dinyatakan dalam angka-angka, maka kumpulan angka-angka hasil observasi atau pengukuran yang demikian itu dinamakan data kuantitatif. Ada juga observasi yang bersifat kualitatif yaitu berupa serangkaian observasi dimana tiap observasi yang terdapat dalam sampel (atau populasi) tergolong dalam salah satu kelas yang saling lepas (mutually exclusive) dan yang kemungkinannya tidak dapat dinyatakan dalam angkaangka".

Di dalam penelitian ini penulis menggunakan metodologi penelitian deskriptif kuantitatif.Di mana penulis meneliti berdasarkan pengalaman penulis sewaktu training di hotel tersebut dan berdasarkan perhitungan angket yang sudah disebarkan kepada karyawan-karyawan di bagian housekeeping guna mengetahui hubungan motivasi kerja dalam meningkatkan kinerja room attendant Novotel Nusa Dua Bali. 


\section{National Conference of Creative Industry: Sustainable Tourism Industry for Economic Development}

Universitas Bunda Mulia, Jakarta, 5-6 September 2018 e-ISSN No: 2622 - 7436

Motivasi menjadi salah satu indikator pengukuran kinerja, karena motivasi sebagai sikap pimpinan dan karyawan terhadap situasi kerja di lingkungan organisasi mereka. Jika karyawan bersifat positif terhadap situasi kerjanya akan menunjukan motivasi kerja tinggi yang akan mengahasilkan kinerja yang maskimal. Sebaliknya jika karyawan bersifat negatif terhadap situasi kerjanya akan menunjukan motivasi kerja yang rendah

Menurut Kusmayadi ( 1999: 73 ) unit analisis adalah unit yang diamati dan akan dijelaskan, serta merupakan objek penelitian yang dapat berupa individu perorangan, kelompok organisasi, masyarakat, hasil karya manusia, instansi, dan sebagainya. Untuk judul "Motivasi kerja dalam meningkatkan kinerja room attendant Novotel Nusa Dua Bali" unit analisisnya terdiri atas individu room attendant dan juga Floor Supervisor

\section{Metode Analisis Data}

1. Skala Likert

Di dalam buku Metodelogi Penelitian Pariwisata dan Perhotelan, I Gusti dan Ni Made Eka Mahadewi (2012:60), skala ini dikembangkan oleh Rensis Likert (1932) yang paling sering digunakan untuk mengukur sikap, pendapat, persepsi respondenn terhadap suatu obyek. Bentuk sederhana skala likert adalah 1-5, dimana arti dari angka itu adalah

$5=$ sangat setuju

$4=$ setuju

$3=$ ragu-ragu

2 = tidak setuju

1 = sangat tidak setuju

Dalam proyek akhir ini penulis menggunakan Skala Likert untuk menghitung hasil kuisioner yaitu berupa pertanyaan-pertanyaan yang penulis berikan kepada karyawan-karyawan di bagian housekeeping. Pertanyaan-pertanyaan berhubungan dengan topik penelitian hubungan motivasi kerja dalam meningkatkan kinerja room attendant Novotel Nusa Dua Bali. Jenis pertanyaan yang diajukan dalam kuesioner adalah pertanyaan tertutup, responden hanya memilih satu jawaban yang dianggap paling tepat dari enam pilihan jawaban yang tersedia.

Jawaban setiap butir pertanyaan yang menggunakan Skala Likert mempunyai gradasi bobot antara lain:

Untuk Variabel X

Bobot nilai 5 untuk jawaban Sangat Setuju (SS)

Bobot nilai 4 untuk jawaban Setuju (S)

Bobot nilai 3 untuk jawaban Ragu-ragu $(\mathrm{RG})$

Bobot nilai 2 untuk jawaban Kurang Setuju (KS)

Bobot nilai 1 untuk jawaban Sangat Tidak Setuju (STS)

Untuk Variabel Y

Bobot nilai 5 untuk jawaban Sangat Setuju (SS)

Bobot nilai 4 untuk jawaban Setuju (S)

Bobot nilai 3 untuk jawaban cukup setuju (CS)

Bobot nilai 2 untuk jawaban kurang Setuju (KS)

Bobot nilai 1 untuk jawaban Sangat Tidak Setuju (STS)

2. Analisis korelasi

Untuk mengukur korelasi antara motivasi kerja dalam meningkatkan kinerja room attendant di Novotel Nusa Dua atau untuk menentukan suatu besaran yang dinyatakan seberapa 
kuatnya hubungan antara kedua variabel tersebut, sangat lemah atau tidak terdapat hubungan sama sekali, maka digunakan rumus Pearson Product Moment

a) Rumus Pearson Product Moment : $\quad r=\frac{n\left(\sum x y\right)-\left(\sum x\right)\left(\sum y\right)}{\sqrt{n\left(\sum x^{2}\right)-\left(\sum x\right)^{2}} \cdot \sqrt{n\left(\sum y^{2}\right)-\left(\sum y\right)^{2}}}$

Keterangan:

$\mathrm{r}:$ Korelasi Pearson Product Moment

$\mathrm{n}$ : Jumlah Sampel

$\mathrm{x}$ : Nilai Motivasi Kerja

y : Nilai Kinerja

Besar korelasi Pearson Product Moment dengan lambang (r) harus :

Keterangan:

$-1 \leq r \leq+1$

$\mathrm{r}=-1$ Korelasi negatif sempurna (hubungan $\mathrm{x}$ dan $\mathrm{y}$ tidak searah)

$\mathrm{r}=0$ Tidak ada korelasi

$\mathrm{r}=+1$ Korelasi sangat kuat (hubungan $\mathrm{x}$ dan $\mathrm{y}$ searah)

Tabel

Interval Nilai Koefisien Korelasi dan Kekuatan Hubungan

\begin{tabular}{|c|c|c|}
\hline NO & $\begin{array}{c}\text { INTERVAL } \\
\text { NILAI }\end{array}$ & $\begin{array}{c}\text { KETERANGAN } \\
\text { HBUNGAN }\end{array}$ \\
\hline 1 & 0,00 & Tidak ada \\
\hline 2 & $0,01-0,20$ & $\begin{array}{c}\text { Sangat rendah } \\
\text { atau lemah } \\
\text { sekali }\end{array}$ \\
\hline 3 & $0,21-0,40$ & $\begin{array}{c}\text { Rendah atau } \\
\text { lemah tapi pasti } \\
\text { Cukup berarti } \\
\text { atau sedang }\end{array}$ \\
\hline 4 & $0,41-0,70$ & $\begin{array}{c}\text { Tinggi atau kuat } \\
\text { Sangat tinggi } \\
\text { atau kuat sekali } \\
\text { Sempurna }\end{array}$ \\
\hline 5 & $0,71-0,90$ \\
\hline 6 & $0,90-1,00$ \\
\hline 7 & 1,00 & \\
\hline
\end{tabular}

b) Koefisien penentu (KP)

Untuk lebih mengetahui seberapa jauh hubungan motivasi kerja dalam meningkatkan kinerja room attendant, maka dapat menggunakan koefisien penentu (KP).

$$
\mathrm{KP}=\mathrm{r}^{2} \times 100 \%
$$

Keterangan:

$\mathrm{KP}=$ Koefisien penentu

$\mathrm{r}=$ Koefisien Hubungan

1. Uji Hipotesis

Setelah menentukan Koefisien Penentu selanjutnya dilakukan pengujian dua arah dengan hipotesis statistik, sebagai berikut: 
Ho $: \rho=0$, artinya variabel $\mathrm{x}$ (hubungan motivasi kerja) dengan variabel y (kinerja room attendant) tidak mempunyai hubungan positif.

Ha $: \rho=\neq 0$, artinya antara variabel $\mathrm{x}$ (hubunganmotivasi kerja) dengan variabel y (kinerja room attendant) mempunyai hubungan positif.

rumus yang digunakan:

$$
t=\frac{r \sqrt{n-2}}{\sqrt{1-r^{2}}}
$$

Kriteria :

a) $\quad t$ tabel $<\mathrm{t}$ hitung $<+\mathrm{t}$ tabel ; Ho diterima Ha ditolak berarti tidak ada hubungan yang cukup berarti diantara variabel yang diteliti.

b) $\quad t$ hitung $>\mathrm{t}$ tabel atau $\mathrm{t}$ hitung $<-\mathrm{t}$ tabel, maka Ho ditolak $\mathrm{H}$ diterima, berarti terdapat hubungan yang cukup berarti diantara variabel yang diteliti.

\section{HASIL PENELITIAN DAN PEMBAHASAN}

\section{Profil Responden}

Didalam penelitian ini penulis mengambil responden sebanyak 19 orang room attendant di Housekeeping Department hotel Novotel Nusa Dua. Adapun profil responden diantaranya :

Tabel 1. Profil responden berdasarkan jenis kelamin

\begin{tabular}{|l|l|l|}
\hline Jenis Kelamin & Jumlah & \multicolumn{1}{|c|}{$\%$} \\
\hline Pria & $\begin{array}{l}19 \\
\text { Orang }\end{array}$ & $100 \%$ \\
\hline Wanita & - & $0 \%$ \\
\hline Total & $\begin{array}{l}19 \\
\text { Orang }\end{array}$ & $100 \%$ \\
\hline
\end{tabular}

Pada tabel di atas diketahi bahwa sebagian besar room attendant di Housekeeping Department adalah Pria $100 \%$ \% dikarenakan pekerjaan sebagai seorang room attendant lebih banyak menggunakan fisik.

Tabel 2. Profil responden berdasarkan Usia

\begin{tabular}{|l|l|l|}
\hline \multicolumn{1}{|c|}{ Umur } & Jumlah & \multicolumn{1}{c|}{$\%$} \\
\hline 18-28 Tahun & $\begin{array}{l}10 \\
\text { Orang }\end{array}$ & $\begin{array}{l}52.64 \\
\%\end{array}$ \\
\hline 29-39 Tahun & 7 Orang & $\begin{array}{l}36.84 \\
\%\end{array}$ \\
\hline 40-50 Tahun & 2 orang & $\begin{array}{l}10.52 \\
\%\end{array}$ \\
\hline Diatas 50 tahun & - & - \\
\hline Total & $\begin{array}{l}19 \\
\text { Orang }\end{array}$ & $100 \%$ \\
\hline
\end{tabular}


National Conference of Creative Industry:

Sustainable Tourism Industry for Economic Development

Universitas Bunda Mulia, Jakarta, 5-6 September 2018

e-ISSN No: 2622 - 7436

Pada tabel di atas diketahui bahwa sebagian besar room attendant di Housekeeping Department berumur 18-28 tahun dikarenakan umur 18-28 tahun merupakan umur yang masih produktif.Sehingga para karyawan dapat bekerja dengan baik dan mempunyai kestabilan kerja yang tinggi.

Tabel 3. Profil responden berdasarkan latar belakang pendidikan

\begin{tabular}{|l|l|l|}
\hline \multicolumn{1}{|c|}{$\begin{array}{c}\text { Latar belakang } \\
\text { pendidikan }\end{array}$} & Jumlah & \multicolumn{1}{c|}{$\%$} \\
\hline SMU/sederajat & - & - \\
\hline Diploma 1 & $\begin{array}{l}8 \\
\text { Orang }\end{array}$ & $42.11 \%$ \\
\hline Diploma 2 & $\begin{array}{l}8 \\
\text { Orang }\end{array}$ & $42.11 \%$ \\
\hline Diploma 3 & $\begin{array}{l}3 \\
\text { Orang }\end{array}$ & $15.78 \%$ \\
\hline Diploma 4 atau S1 & - & - \\
\hline Total & $\begin{array}{l}19 \\
\text { Orang }\end{array}$ & $100 \%$ \\
\hline
\end{tabular}

Pada tabel di atas dinyatakan responden terhadap latar belakang pendidikan karyawan dengan latar belakang diploma lebih mendominasi.Jadi dapat disimpulkan berdasarkan latar belakang pendidikan room attendant adalah mereka yang berkompeten.

Tabel 4. Profil responden berdasarkan masa kerja

\begin{tabular}{|l|l|l|}
\hline \multicolumn{1}{|c|}{ Masa Kerja } & Jumlah & \multicolumn{1}{c|}{$\%$} \\
\hline 1-3 tahun & 6 Orang & $31.58 \%$ \\
\hline $3-5$ tahun & 13 Orang & $68.42 \%$ \\
\hline $5-8$ tahun & - & - \\
\hline$>16$ tahun & - & - \\
\hline Total & 19 Orang & $100 \%$ \\
\hline
\end{tabular}

pada tabel diatas diketahui bahwa rata-rata room attendant adalah mereka yang sudah lama bekerja di Novotel Nusa Dua karena rata-rata masa kerjanya sudah lebih dari 3 tahun. Dengan pengalaman ini tentunya dapat dilihat loyalitas serta penguasaan terhadap lingkungan kerja oleh karyawam.

Tabel 5. Rekapitulasi Responden

\begin{tabular}{|l|l|l|}
\hline No Responden & PERTANYAAN & TOTAL \\
\hline
\end{tabular}


National Conference of Creative Industry:

Sustainable Tourism Industry for Economic Development

Universitas Bunda Mulia, Jakarta, 5-6 September 2018

e-ISSN No: 2622 - 7436

\begin{tabular}{|c|c|c|c|c|c|c|c|c|c|c|c|}
\hline & 1 & 2 & 3 & 4 & 5 & 6 & 7 & 8 & 9 & 10 & \\
\hline 1 & 4 & 3 & 4 & 3 & 4 & 4 & 4 & 4 & 4 & 3 & 37 \\
\hline 2 & 3 & 4 & 3 & 3 & 3 & 4 & 4 & 4 & 4 & 3 & 35 \\
\hline 3 & 4 & 4 & 4 & 4 & 4 & 5 & 5 & 4 & 5 & 4 & 43 \\
\hline 4 & 4 & 4 & 4 & 3 & 4 & 3 & 4 & 3 & 5 & 4 & 38 \\
\hline 5 & 4 & 3 & 4 & 3 & 4 & 4 & 3 & 4 & 4 & 3 & 36 \\
\hline 6 & 4 & 4 & 4 & 4 & 3 & 3 & 5 & 4 & 5 & 4 & 40 \\
\hline 7 & 5 & 4 & 3 & 4 & 5 & 5 & 4 & 4 & 5 & 5 & 44 \\
\hline 8 & 3 & 4 & 3 & 4 & 4 & 3 & 4 & 3 & 4 & 3 & 35 \\
\hline 9 & 4 & 4 & 4 & 3 & 4 & 3 & 4 & 4 & 3 & 4 & 37 \\
\hline 10 & 4 & 4 & 5 & 4 & 5 & 5 & 5 & 4 & 4 & 5 & 45 \\
\hline 11 & 5 & 4 & 4 & 5 & 4 & 5 & 4 & 5 & 5 & 4 & 45 \\
\hline 12 & 4 & 4 & 4 & 4 & 4 & 4 & 4 & 5 & 4 & 4 & 41 \\
\hline 13 & 4 & 4 & 4 & 5 & 5 & 5 & 4 & 5 & 4 & 4 & 44 \\
\hline 14 & 4 & 4 & 3 & 4 & 4 & 4 & 4 & 4 & 4 & 3 & 38 \\
\hline 15 & 4 & 4 & 5 & 4 & 4 & 4 & 5 & 4 & 4 & 4 & 42 \\
\hline 16 & 4 & 3 & 4 & 4 & 4 & 4 & 4 & 4 & 5 & 5 & 41 \\
\hline 17 & 3 & 3 & 4 & 4 & 3 & 3 & 4 & 4 & 4 & 4 & 36 \\
\hline 18 & 3 & 4 & 4 & 4 & 4 & 4 & 4 & 4 & 4 & 4 & 39 \\
\hline 19 & 4 & 4 & 3 & 4 & 4 & 3 & 4 & 5 & 3 & 4 & 38 \\
\hline TOTAL & 74 & 72 & 73 & 73 & 76 & 75 & 79 & 78 & 80 & 74 & 754 \\
\hline
\end{tabular}

Tabel 6. Analisa kofesien korelasi

\begin{tabular}{|c|c|c|c|c|c|}
\hline NO & X & Y & X2 & Y2 & XY \\
\hline 1 & 40 & 37 & 1600 & 1369 & 1480 \\
\hline 2 & 37 & 35 & 1369 & 1225 & 1295 \\
\hline 3 & 43 & 43 & 1849 & 1849 & 1849 \\
\hline 4 & 39 & 38 & 1521 & 1444 & 1482 \\
\hline 5 & 37 & 36 & 1369 & 1296 & 1332 \\
\hline 6 & 45 & 40 & 2025 & 1600 & 1800 \\
\hline 7 & 45 & 44 & 2025 & 1936 & 1980 \\
\hline 8 & 35 & 35 & 1225 & 1225 & 1225 \\
\hline 9 & 44 & 37 & 1936 & 1369 & 1628 \\
\hline
\end{tabular}


National Conference of Creative Industry: Sustainable Tourism Industry for Economic Development Universitas Bunda Mulia, Jakarta, 5-6 September 2018 e-ISSN No: 2622 - 7436

\begin{tabular}{|c|c|c|c|c|c|}
10 & 45 & 45 & 2025 & 2025 & 2025 \\
\hline 11 & 41 & 45 & 1681 & 2025 & 1845 \\
\hline 12 & 46 & 41 & 2116 & 1681 & 1886 \\
\hline 13 & 44 & 44 & 1936 & 1936 & 1936 \\
\hline 14 & 36 & 38 & 1296 & 1444 & 1368 \\
\hline 15 & 45 & 42 & 2025 & 1764 & 1890 \\
\hline 16 & 45 & 41 & 2025 & 1681 & 1845 \\
\hline 17 & 39 & 36 & 1521 & 1296 & 1404 \\
\hline 18 & 37 & 39 & 1369 & 1521 & 1443 \\
\hline 19 & 39 & 38 & 1521 & 1444 & 1482 \\
\hline TOTAL & 782 & 754 & 32434 & 30130 & 31195 \\
\hline
\end{tabular}

$$
\begin{array}{ll}
\mathrm{n} & =19 \\
\sum \mathrm{x} & =782 \\
\sum \mathrm{y} & =754 \\
\sum \mathrm{x}^{2} & =32434 \\
\sum \mathrm{y}^{2} & =30130 \\
\sum \mathrm{xy} & =31195
\end{array}
$$

a. Korelasi Product Moment Pearson

Analisa koefisien korelasi digunakan untuk menentukan bentuk dan jenis hubungan korelasi antara motivasi dan kinerja room attendant, dimana rumus yang digunakan adalah koefiien korelasi product moment, sebagai berikut :

$$
\begin{aligned}
& r=\frac{3077}{\sqrt{18670788}} \\
& \begin{aligned}
r & =\frac{n\left(\sum x y\right)-\left(\sum x\right)\left(\sum y\right)}{\sqrt{n\left(\sum x^{2}\right)-\left(\sum x\right)^{2}} \cdot \sqrt{n\left(\sum y^{2}\right)-\left(\sum y\right)^{2}}} \\
r & =\frac{19(31195)-(782)(754)}{\sqrt{19(32434)-(782)^{2}} \cdot \sqrt{19(30130)-(754)^{2}}} \\
r & =\frac{592705-589628}{\sqrt{(616246)-(611524)} \cdot \sqrt{(572470)-(568516)}} \\
r & =\frac{3077}{\sqrt{4722} \cdot \sqrt{3954}}
\end{aligned} \\
& r=\frac{3077}{4320.971} \\
& r=0.71
\end{aligned}
$$

Berdasarkan perhitungan koefisien korelasi antara variable $\mathrm{X}$ dan variable $\mathrm{Y}$ dapat diketahui nilai $r$ adalah 0,71( Interval koefisien 0,71-0,90 memiliki tingkat hubungan yang tinggi atau kuat 


\section{National Conference of Creative Industry: \\ Sustainable Tourism Industry for Economic Development}

Universitas Bunda Mulia, Jakarta, 5-6 September 2018

e-ISSN No: 2622 - 7436

dan dapat diandalkan). Ini berarti bahwa antara motivasi dan kinerja room attendant terhadap hubungan (korelasi) yang tinggi atau kuat. Ini berarti bahwa antara motivasi terhadap kinerja room attendant berhubungan satu sama lainnya.

b. Analisis Koefisien Penentu

Analisis koefisien penentu digunakan unntuk mengetahui besarnya pengaruh antara motivasi terhadap kinerja room attendant, dengan menggunakan rumus:

$\mathrm{KP}=\mathrm{r}^{2} \times 100 \%$

$\mathrm{KP}=0,71^{2} \times 100 \%$

$\mathrm{KP}=50,41 \%$

Dari hasil perhitungan di atas, terlihat nilai dari koefisien penentunya sebesar $50,41 \%$. Ini berarti bahwa besarnya kontribusi motivasi terhadap terhadap kinerja sebesar $50.41 \%$, selebihnya sebesar $49.59 \%$ dipengaruhi oleh faktor - faktor lain, yang tidak ada dalam penelitian.Maka dapat disimpulkan bahwa motivasi berpengaruh terhadap kinerja room attendant.

c. Uji Hipotesis

Hasil perhitungan dari koefisien korelasi diuji untuk mengetahui kesignifikan, yaitu apakah antara motivasi kerja dan kinerja merupakan suatu hubungan yang nyata atau tidak (signifikan atau tidak). Sehingga penulis melakukan pengujian sebagai berikut:

Ho $: \rho=0$, artinya variabel $\mathrm{x}$ (hubungan motivasi) dengan variabel y (kinerja room attendant) tidak mempunyai hubungan positif.

Ha $: \rho=\neq 0$, artinya antara variabel $\mathrm{x}$ (hubungan motivasi) dengan variabel y (kinerja)mempunyai hubungan positif.

Dapat dirumuskan sebagai berikut:

T hitung :

$\mathrm{t}=r \sqrt{\frac{n-2}{1-r^{2}}}$

$\mathrm{t}=0,71 \sqrt{\frac{19-2}{1-0,71^{2}}}$

$\mathrm{t}=0,71 \frac{\sqrt{17}}{1-0,5041}$

$\mathrm{t}=0,71 \sqrt{\frac{17}{0.4959}}$

$\mathrm{t}=0,71 \sqrt{34,281} 1$

$\mathrm{t}=0,71.5,855$

$\mathrm{t}=4,157$

T tabel:

$\mathrm{t}=\mathrm{n}-2$

$=19-2$

$=17$

Di dalam penelitian terdapat hasil $\mathrm{t}$ hitung 4,157 dan $\mathrm{t}$ tabelnya 2,110. Dapat disimpulkan thitungnya $=4,157>\mathrm{t}$ tabel $=2.110$ maka Ha diterima Ho ditolak. Ini berarti bahwa antara motivasi dan kinerja room attendant terdapat hubungan yang signifikan.

\section{KESIMPULAN DAN IMPLIKASI}

1. Kofesien korelasi 


\section{National Conference of Creative Industry: \\ Sustainable Tourism Industry for Economic Development}

Universitas Bunda Mulia, Jakarta, 5-6 September 2018

e-ISSN No: 2622 - 7436

Berdasarkan perhitungan koefisien korelasi antara variabel $\mathrm{X}$ dan variabel Dpat diketahui nilai $\mathrm{r}$ adalah 0,71 ( Interval koefisien 0,11 - 0,90 memiliki tingkat hubungan yang sangat tinggi atau kuat sekali dan dapat diandalkan). Ini berarti bahwa antara motivasi terhadap kinerja room attendant berhubungan satu sama lainnya

2. Koefisien Penentu

Dari hasil perhitungan di atas, terlihat nilai dari koefisien penentunya sebesar $50,41 \%$. Ini berarti bahwa besarnya kontribusi motivasi terhadap kinerja room attendant sebesar 50,41\%. Selebihnya sebesar 49,59\% dipengaruhi oleh faktor - faktor lain, yang tidak ada dalam penelitian.

3. Uji Hipotesis

Di dalam penelitian terdapat hasil t hitung 4.157 dan t tablenya 17. Dapat disimpulkan t hitungnya $=4157>$ t 0,05 . $17=2,110$ maka Ha diterima Ho ditolak.Ini berarti bahwa antara motivasi dan kinerja room attendant terdapat hubungan yang signifikan.

\section{DAFTAR PUSTAKA}

Gouzaly, Saydam. (2002). Manajemen Sumber Daya Manusia.Jakarta: Gunung Agung. Hasan, Iqbal, (2002). Metodologi penelitian dan aplikasinya.Jakarta :Ghalia indonesia Hasibuan, Melayu SP, (2001). Managemen sumber daya manusia, Yogyakarta : Andi

Kusmayadi, Endar Sugiarto, (2000). Metodologi penelitian dalam bidan pariwisata, Jakara : Gramedia pustaka utama

Luthans.Fred, (2006).Perilaku organisasi, Yogyakarta : Andi

Mangkunegara, A.A, Prabu, (2005). Evaluasi kinerja SDM, Bandung :Aditama

Rumekso, (2004).Housekeeping hotel.Yogyakarta : Andi

Sedarmayanti.2001. Sumber Daya Manusia dan Produktivitas Kerja.

Bandung : Mandar Maju.

Sugiyono, (2011).Metodologi penelitian kuantitatif kualitatif dan $R \& D$ :Bandung

Winardi,J , (2001). Motivasi permotivasian dalam manajemen, bandung : Raja Grafindo Persada. Wisnu Hs, Al Bataafi, (2006). Housekeeping department floor \& public area. Bandung : Alfabeta 